\title{
The effect of digital marketing capabilities on organizational ambidexterity of the information technology sector
}

\author{
Emad Tariq ${ }^{a}$, Muhammad Alshurideh ${ }^{b^{*}}$, Iman Akour ${ }^{c}$ and Sulieman Al-Hawary ${ }^{d}$
}

${ }^{a}$ Department of Logistics, Marketing, Hospitality and Analytic. University of Huddersfield, United Kingdom

${ }^{b}$ Department of Marketing, School of Business, The University of Jordan, Jordan

${ }^{c}$ University of Sharjah, United Arab Emirates

${ }^{d}$ Department of Business Administration, Faculty of economics and Administrative sciences, Al al-Bayt University, Mafraq, Jordan

C H R O N I C L E

Article history:

Received: October 2, 2021

Received in revised format: No-

vember 18, 2021

Accepted: December 25, 2021

Available online: December 25, 2021

Keywords:

Digital Marketing Capabilities Organizational Ambidexterity

Information Technology Sector $U A E$

\section{A B S T R A C T}

The aim of the study was to examine the impact of digital marketing capabilities on organizational ambidexterity by focusing on the Information Technology Sector in UAE. Data were primarily gathered through self-reported questionnaires created by Google Forms which were distributed to a purposive sample of managers at different levels via email. This study was conducted structural equation modeling (SEM) to test the hypotheses, which represents a contemporary statistical technique for testing and estimating the relationship between factors and variables. The results showed that the highest impact on organizational ambidexterity was for strategic approach and data content infrastructure, followed by integrating customers with employees, and finally the lowest impact belonged to the process of improving performance. Based on the study findings, the researcher hopes that the decision-makers and managers define all tasks, roles and work procedures in companies through digital marketing systems to improve their organizational ambidexterity and enhance their performance.

\section{Introduction}

Marchese and Dollar (2015) pointed out that companies need to differentiate themselves in organizational ambidexterity by simultaneously exploring and exploiting opportunities in the company's learning processes context. Although there is a general thought that companies are required to simultaneously engage in exploration and exploitation for short-term performance and long-term survival (O'Rielly \& Tushman, 2013; Birkinshaw \& Gupta, 2013). There is little agreement on how organizational ambidexterity is exercised through the organizational ambidexterity practices (exploration and exploitation of opportunities) clearly in the company. company's vital operating system through its existed organizational capabilities, including digital marketing capabilities, is responsible for up to $90 \%$ of company's cost base (IMA, 2008), This is allowed by new technologies and practices that provide digital marketing architecture and improvements (Organizational ambidexterity Practices: Exploring and Exploiting Opportunities) (Marchese \& Dollar, 2015), Therefore, many organizations have tried to find many methods to achieve their strategic superiority as a result of tremendous technological progress in order to reach strategic success at industry and the market together (Altarifi et al., 2015; Al-Nady et al., 2016; Al-Hawary \& Al-Syasneh, 2020 ). One of these methods is to exploit digital marketing capabilities by focusing on 7 core capabilities which are strategic approach, performance improvement process, management buy-in, resourcing and structure, data and infrastructure, integrated customer communications and customer experience in order to disseminate digital marketing in digital marketing environment to creating

* Corresponding author.

E-mail address: malshurideh@sharjah.ac.ae (M. Alshurideh)

(C) 2022 by the authors; licensee Growing Science, Canada. doi: $10.5267 /$ j.ijdns.2021.12.014 
integration between different departments and sections, so that this method is an aid tool in achieving organizational ambidexterity at organization, market and industry (Al-Hawary et al., 2018; Al-Hawary \& Alhajri, 2020; Al-Hawary et al., 2012; Al-Hawary \& Mohammad, 2011 ). The study topic is considered as an important topic in the Arab management literature, in addition to the lack of studies related to it, so the study maybe a cornerstone for researchers, study importance also comes from the practical recommendations that will result for decision-makers in these companies to benefit in improving organizational ambidexterity by exploiting digital marketing capabilities. Hence the idea of the researchers to identify the impact of digital marketing capabilities on organizational ambidexterity.

\section{Literature review and hypothesis development}

\subsection{Digital marketing capabilities}

Organizations are interested in the concept of digital marketing, based on their interest in making routine and strategic decisions processes, and its reflection on companies' organizational operation, and this interest comes from the competition volume and challenges that these companies face in providing and securing customers' needs, especially that global markets have become the focus of all companies in the world attention. This interest also comes from the need for a set of systems that analyze and present daily reports, which help managers in making decisions, in addition to monitoring the work of organizational units, especially strategic ones. Digital marketing capabilities are considered one of the smart systems necessary to know the mechanisms of achievement, work and decision-making that enhances the possibility of foreseeing the organization's future strategic direction (Emad, 2021). As digital marketing systems represent one of the modern approaches that work to collect and analyze data with the aim of using it in the organizations operating in the field of industry. There is no agreed definition of digital marketing capabilities in the management literature. In fact, each researcher emphasizes different aspects (Wasmann \& Strout, 2012). In a broader sense, the term is understood as a management philosophy that helps explain a complex business environment to identify the best possible solutions. (Hocevar \& Jaklic 2010). In general, the term Digital marketing (BI) is defined as "the set of processes, knowledge, methodologies, practices, applications and technologies which aim to effectively and efficiently adopt management activities and to make improved business decisions in a timely manner" (Gartner, 2016). Academics identified the digital marketing capabilities to seven core which are strategic approach, performance improvement process, management buy-in, resourcing and structure, data and infrastructure, integrated customer communications and customer experience (Herhausen et al., 2020). Digital marketing capabilities are not implemented individually but are made up of components that are interlinked and must work together to deliver business value. It is important to note that there are a variety of Digital marketing solutions, each serving different needs. The overall structure of BI capabilities includes the following elements: data source, ETL, data warehouse, and analysis and visualization tools as suggested by Hen et al. (2011), The components reflect the four phases of the data processing cycle, such as preprocessing (data cleaning, data selection, and transformation), integration (data merging), data mining, patterns evaluation within the application layer, and data presentation within the presentation layer. The researchers point out that digital marketing is a set of tools and techniques that help transform a large amount of data from various sources into meaningful information to support decision-making and improve organizational performance. Digital marketing (BI) refers to a set of tools and techniques that help transform a large amount of data from disparate sources into meaningful information to support decision-making and improve organizational performance. In the past decade, digital marketing tools have emerged as a major driving force for enhancing organizational performance (Ramakrishnan et al., 2012). Digital marketing systems have improved decision-making effectiveness at different levels in several areas (Popovic et al., 2012). These include the areas of industry in airlines, banking, insurance, finance and securities, manufacturing, telecommunications, and retail (Ramakrishnan et al., 2012). These systems remain the highest priority of organizations ownership (Isik et al., 2013).

Although many organizations have successfully implemented digital marketing systems to support decision-making and organizational performance, not every organization can be proud of this success. For example, in a survey conducted by Information Week magazine of 385 business technology professionals who used digital marketing tools, only $19 \%$ commented that they are successful in using these systems to support and improve business performance in their organizations (Henshen, 2008). Researchers and professionals have looked at digital marketing from different perspectives. Some researchers studied digital marketing as a tool or from a technical perspective (Elbashir, 2008), while others viewed digital marketing as an approach or a tool to support decision-making (Moss \& Atre, 2007). Digital marketing effectiveness lies in its ability to support the decision-making process within the organization and provide decision makers with relevant and timely information (Massa \& Testa, 2005), so organizations struggle to understand the growing diversity, speed and volume of data produced by internal and external sources, and the capabilities of Digital marketing plays an important role in understanding the huge volume of data and helping organizations improve their performance (Isik et al., 2013). Digital marketing capabilities consist of three dimensions:

\section{Digital marketing technology}

It refers to the extent technological readiness to adopt digital marketing in the organization, such as data communication systems, models of digital marketing systems, and interconnecting information systems that help in linking, integrating, data flow, and intelligence across work teams and organization parts, making the organizational structure organized in a smooth and conducive way for decision-making. The technology dimension can also include digital marketing, collaboration, distributed learning, discovery, mapping, opportunity recognition and generation, as well as data and analytics privacy policy (Isik et al., 2013). 
Digital marketing infrastructure structural component refers to the modular organizational design that helps facilitate the engineering of capabilities, functions, and subsequent innovations related to digital marketing. In many cases, organizational structures are logical structures that include the functions or units and divisions within the organization. However, logically constructed structures may sometimes lead to a rigid organization, where information exchange and cooperation across different departments, units and divisions may not occur; leading to a suboptimal function of the effective digital marketing organizational structure, although previous research has been consistent with different organizational structures, such as designing a structure by product or function (Mahone, 1995), hypertext organization that enables easy information exchange and collaboration through a non-hierarchical organizational structure, and a self-organizing structure (Nonaka \& Takeuch, 1995). However, the impact of these structures on digital marketing are not discovered yet, however, the structural adaptation that includes the formal hierarchical structure, with the possibility of achieving a digital marketing structure, - coordination and cooperation to collect and use data, information and intelligence- has a direct impact on motivating the organization to be an effective digital marketing organization.

\section{Digital marketing culture}

In line with technology and structure, a digital marketing culture facilitates an organization's ability to manage organizational data, knowledge, and intelligence. The interaction between individuals and groups is the basis for creating new ideas and creativity. Thus, the existence and consolidation of a more interactive and collaborative culture can transform actual data and/or tacit information into meaningful intelligence and transferring it from individual to organizational level. Employees in such cultural links within the organization can develop the ability to self-regulate the knowledge and practices to find solutions to new or existing problems, thus promoting innovative activities (Isik et al., 2013).

\subsection{Organization ambidexterity}

The term ambidexterity refers to a person's higher skill but is increasingly used by organizational researchers about organizations that are equally skilled at exploiting and exploring activities (Simsek, 2009). Accordingly, each organization tries to be effective in maintaining a high degree of both exploitation and exploration. Previous researchers used the term "ambidexterity" to distinguish between behaviors and outcomes within the organization, Later, ambidexterity concept use in broader refers to an organization's ability to do different things at the same time, such as exploitation and exploration, efficiency and digital marketing architecture, alignment and adaptability, or progressive and radical innovation. Canderasekaran (2009) indicated that ambidexterity refers to individuals ability to apply innovation and improve strategic alternatives to be applied, and this requires the organization to bring activities alignment through the three levels of the organization and alignment of the organization's culture and effective alternatives strategies that require leadership with good attributes, Whereas Simsek (2009) emphasized that ambidexterity works to help organizational units to achieve their jobs more focused on organization activity and ability to exploit opportunities and try to explore opportunities and search for untapped opportunities at the industry.

Organizational ambidexterity can be defined as the organization's ability to efficiently manage current business requirements, and at the same time be adaptive to environmental changes. By being able to use several different structures simultaneously, although researchers argue that it is difficult or even impossible to achieve simultaneous exploration and exploitation, three promising approaches have been identified in the management literature for organizational ambidexterity.

\section{Organizational design approach}

The first approach suggests that organizations can create specific structures to mitigate the tensions between exploration and exploitation, and the irregular process can be enhanced by either spatial separation or parallel structures (Gibson \& Birkinshaw, 2014), Spatial separation means creating separate business units that either explore or exploit (Jansen et al., 2009) and hold these subunits together through corporate culture, shared visions and strategies or management teams (Gibson \& Birkinshaw, 2014).

\section{Context approach}

Contextual solutions are suggested for achieving organization dexterity, although structural approaches separate exploitative and exploratory activities, and dexterity within this context is defined as the ability to simultaneously process and adapt within the same business unit (Zimmermann, Raisch \& Birkinshaw, 2016).

\section{Strategic leadership approach}

Leadership-based antecedents are adopted as a third approach in the literature to achieving organizational ambidexterity. Several researchers suggest that leadership processes are important for structural or contextual inclusion implementation while transformational leadership is related to discovery; transactional leadership is likely to be related to efficiency and incremental changes (O'Reilly and Tushman (2013). In recent years, theoretical work has been supplemented by empirical studies examining the relationship between organizational ambidexterity and company performance. Participation in both exploitative and exploratory operations is crucial to the company's long-term success. A one-sided focus on exploitation may improve performance in the short term, but it may cause long-term difficulties when companies gradually improve their core capabilities, but do not respond adequately to environmental changes. Studies examining the relationship between organizational ambidexterity and company performance have shown mixed results, some studies have found positive relationships between 
organizational ambidexterity and performance (Gibson \& Birkinshaw, 2014; Lubatkin, Simsek, Ling \& Veiga, 2006), while in some studies there are negative relationship ( Atuahene-Gima, 2005), However, the analysis indicates that there is a positive impact on the continuous ambidexterity on company's performance, which increases researchers and managers interest (Junni et al., 2013). According to Bodwell and Chermack (2010) and Cao et al. (2009), organizational ambidexterity consists of:

Exploring Opportunities: It is related to the terms search, variance, risk, experiment, operate, adaptively, and discover creativity. (It refers to learning acquired by processes, coordinated differences, and planned experiences in organizations.

Opportunity Exploitation: It refers to the learning acquired through scientific research, experimental improvement, innovation, reuse of existing procedures and reuse of existing knowledge without any additional learning. It also refers to the continuity of step-by-step and progressively benefiting from what organizations possess.

Based on the description, the following model is proposed.

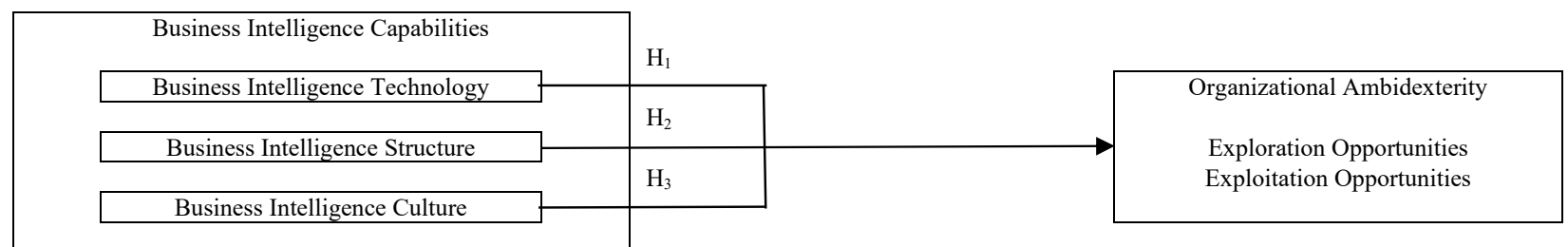

Fig. 1. The proposed study

$\mathbf{H}_{1}$ : There is a statistically significant impact of digital marketing capabilities (digital marketing technology, digital marketing culture, and business structure) on organizational ambidexterity.

\section{Methodology}

\subsection{Population and sample selection}

A qualitative method based on a questionnaire was used in this study for data collection and sample selection. The major aim of the study was to examine the impact of digital marketing capabilities on organizational ambidexterity. Therefore, it focused on of the Information Technology Sector in UAE. Data were primarily gathered through self-reported questionnaires created by Google Forms which were distributed to a purposive sample of managers at different levels via email. In total, (287) responses were received including (15) invalid to statistical analysis due to uncompleted or inaccurate. Hence, the final sample contained (272) responses suitable to analysis requirements, where it proved to be sufficient to the extent that was predictable and allowed for a presumption of data saturation (Sekaran \& Bougie, 2016).

\subsection{Measurement instrument}

A self-reported questionnaire that consists of two main sections along with a section regarding control variables was used as the measurement instrument. Control variables considered as categorical measures were composed of gender, age group, educational level, and experience. The two main sections were dealt with a five-point Likert scale (from 1= strongly disagree to $5=$ strongly agree). The first section contained (16) items to measure digital marketing capabilities based on (Isik et al., 2013). These questions were distributed into dimensions as follows: six items dedicated for measuring digital marketing technology, five items dedicated for measuring digital marketing structure, and five items dedicated for measuring digital marketing culture. Whereas the second section included ten items developed to measure organizational ambidexterity according to what was pointed out by (Bodwell \& Chermack, 2010; Cao; Gedajlovic \& Zhang, 2009). Organizational ambidexterity included two dimensions: exploration opportunities which was measured through five items and exploitation opportunities which was measured by five items.

\section{Findings}

\subsection{Measurement model evaluation}

This study was conducted structural equation modeling (SEM) to test hypotheses, which represents a contemporary statistical technique for testing and estimating the relationship between factors and variables (Wang \&Rhemtulla, 2021). Accordingly, the reliability and validity of the constructs were tested using confirmatory factor analysis (CFA) through the statistical program AMOSv24. Table 1 summarizes the results of convergent and discriminant validity, as well the indicators of reliability. Table 1 shows that the standard loading values for the individual items were within the domain (0.638-0.864), these values greater than the minimum retention of the elements based on their standard loads (Al-Lozi et al., 2018; Sung et al., 2019). Average variance extracted (AVE) is a summary indicator of the convergent validity of constructs that must be above 0.50 (Howard, 2018). The results indicate that the AVE values were greater than 0.50 for all constructs, thus the used measurement 
model has an appropriate convergent validity. Rimkeviciene et al. (2017) suggested the comparison approach as a way to deal with discriminant validity assessment in covariance-based SEM. This approach is based on comparing the values of maximum shared variance (MSV) with the values of AVE, as well as comparing the values of square root of AVE (VAVE) with the correlation between the rest of the structures. The results show that the values of MSV were smaller than the values of AVE, and that the values of $\sqrt{ } \mathrm{AVE}$ were higher than the correlation values among the rest of the constructs. Therefore, the measurement model used is characterized by discriminative validity. The internal consistency measured through Cronbach's Alpha coefficient $(\alpha)$ and compound reliability by McDonald's Omega coefficient $(\omega)$ was conducted as indicators to evaluate the measurement model. The results listed in Table 1 demonstrated that both values of Cronbach's Alpha coefficient and McDonald's Omega coefficient were greater than 0.70 , which is the lowest limit for judging on measurement reliability (de Leeuw et al., 2019).

\section{Table 1}

Results of validity and reliability tests

\begin{tabular}{|c|c|c|c|c|c|}
\hline Constructs & 1 & 2 & 3 & 4 & 5 \\
\hline 1. BIT & 0.755 & & & & \\
\hline 2. BIS & 0.591 & 0.767 & & & \\
\hline 3. $\mathrm{BIC}$ & 0.552 & 0.573 & 0.732 & & \\
\hline 4. EXR & 0.625 & 0.597 & 0.660 & 0.757 & \\
\hline 5. EXI & 0.681 & 0.605 & 0.638 & 0.625 & 0.762 \\
\hline VIF & 1.899 & 2.052 & 1.764 & --- & --- \\
\hline Loadings range & $0.638-0.846$ & $0.651-0.835$ & $0.692-0.794$ & $0.681-0.831$ & $0.675-0.864$ \\
\hline AVE & 0.570 & 0.589 & 0.535 & 0.573 & 0.581 \\
\hline MSV & 0.372 & 0.506 & 0.482 & 0.515 & 0.498 \\
\hline Internal consistency & 0.886 & 0.874 & 0.850 & 0.867 & 0.871 \\
\hline Composite reliability & 0.888 & 0.877 & 0.852 & 0.870 & 0.873 \\
\hline
\end{tabular}

Note: BIT: digital marketing technology, BIS: digital marketing structure, BIC: digital marketing culture, EXR: exploration opportunities, EXI: exploitation opportunities, Bold fonts refer to square root of average variance extracted.

\subsection{Structural model}

The structural model illustrated no multicollinearity issue among predictor constructs because variance inflation factor (VIF) values are below the threshold of 5, as shown in Table 1 (Hair et al., 2017). This result is supported by the values of model fit indices shown in Fig. 1.

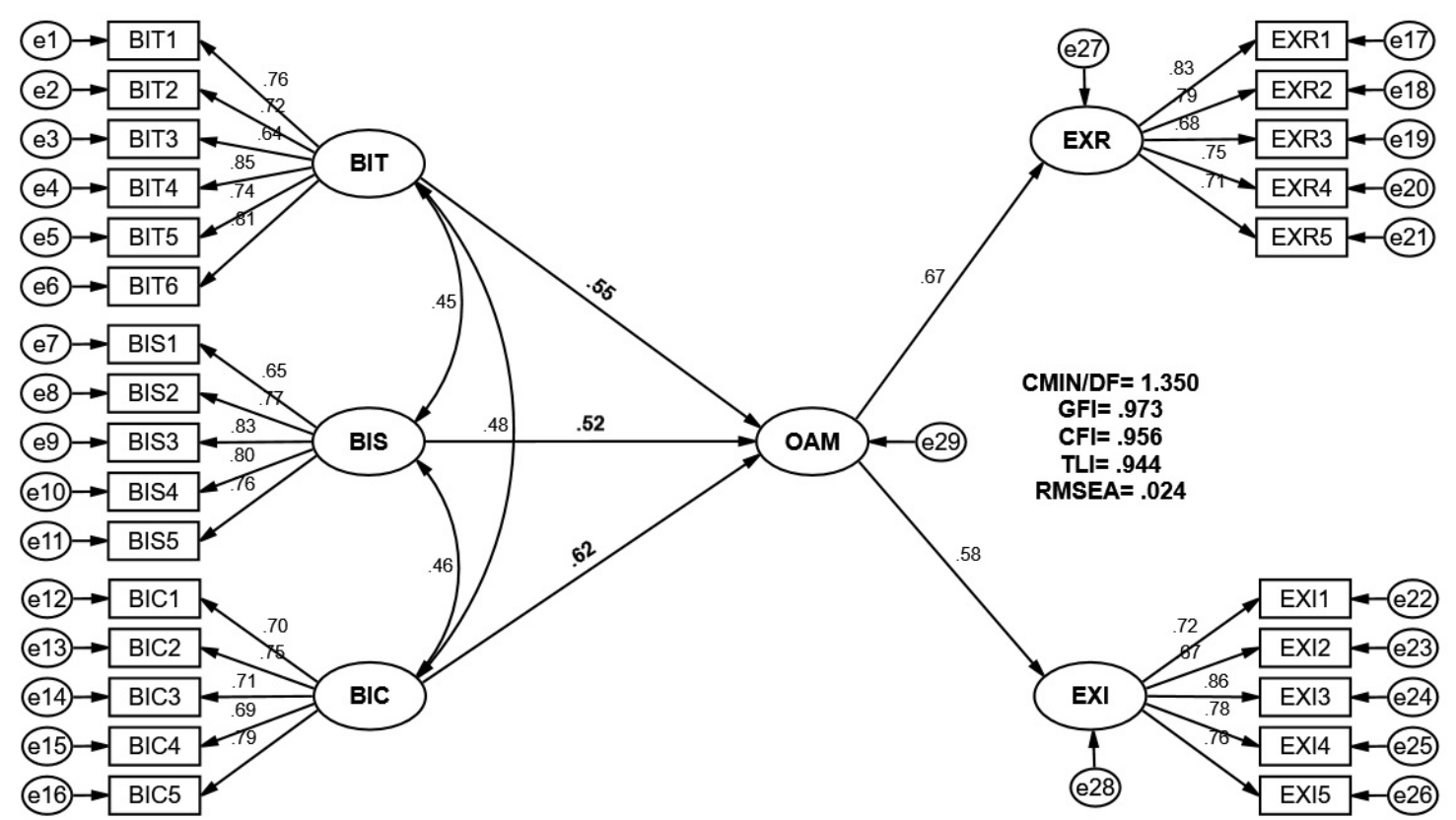

Fig. 2. SEM results of the digital marketing capabilities effect on organizational ambidexterity

The results in Fig. 2 indicate that the chi-square to degrees of freedom (CMIN/DF) was 1.350, which is less than 3 the upper limit of this indicator. The values of the goodness of fit index (GFI), the comparative fit index (CFI), and the Tucker-Lewis index (TLI) were higher than the minimum accepted threshold of 0.90 . Moreover, the result of root means square error of approximation (RMSEA) indicated to value 0.024 , this value is a reasonable error of approximation because it is less than the 
higher limit of 0.08. Consequently, the structural model used in this study was recognized as a fit model for predicting the DEP and generalization of its result (Ahmad et al., 2016; Shi et al., 2019). To verify the results of testing the study hypotheses, structural equation modeling (SEM) was used, the results of which are listed in Table 2.

Table 2

Hypothesis testing

\begin{tabular}{lllc}
\hline Hypothesis & Relation & Standard Beta & $p$ value \\
\hline H1 & BIT $\rightarrow$ OAM & $0.551^{* * *}$ & 0.000 \\
H2 & BIS $\rightarrow$ OAM & $0.525^{* * *}$ & 22.62 \\
H3 & BIC $\rightarrow$ OAM & $0.619^{* * *}$ & 20.25 \\
\hline
\end{tabular}

Note:BIT: digital marketing technology, BIS: digital marketing structure, BIC: digital marketing culture, OAM: organizational ambidexterity, * $p<0.05$, $* * p<0.01, * * * p<0.001$.

The results demonstrated in Table 2 show that the highest impact was for digital marketing culture $(\beta=0.619, t=26.85, p=$ $0.000)$, followed by digital marketing technology $(\beta=0.551, t=22.62, p=0.000)$, and finally the lowest impact was for digital marketing structure $(\beta=0.525, t=20.25, p=0.000)$. Thus, all the minor hypotheses of the study were supported based on these results.

\section{Discussion}

Looking at digital marketing culture levels as digital marketing capabilities practices dimension, it is noted that its importance was medium. The researchers believe that this result indicates that companies are working with average interest to make cultural adjustment for individuals in the surveyed companies, especially with regard to employees' understanding of digital marketing culture importance in terms of enhancing the surveyed company's capabilities and success. To enhance this culture, companies are working hard to encourage employees to explore intelligence and experimentation and support senior management in these companies and enhance digital marketing capabilities and culture through using software packages to support this culture. They also participate in developing and exchanging digital marketing experiences through training on digital marketing by job learning and try to benefit its capabilities towards achieving digital marketing vision and goal and make this vision and goals clear and understandable. It was also found that digital marketing structuring level was moderate, as it was found that companies, through their existing structure between departments and divisions, promote information exchange and sharing based on digital marketing software. It is also working to practice the application of collective intelligence instead of relying on individual intelligence in activities and work conducting, which makes it able to develop and discover any new intelligences, this usually is based on motivation, which strengthens the information transfer through digital marketing software across different units and departments. It was also found that companies are moderately interested in digital marketing practices in terms of documenting processes, formulating and classifying product knowledge, As well as t digital marketing capabilities use in documenting, coordinating and classifying customer-related production and service processes, As well as in reviewing and completing operations and providing services, to collaborate with individuals within the company and external customers, to review the market and competition, to seek new knowledge and to allow employees in multiple locations to learn as a group from one source at the same time.

The results indicated that companies' management is able to exploit available opportunities to excel their products provision and work to modify the current products by adapting with customers desires to satisfy them in an attempt to find simple and uncomplicated products that give the products a kind of improvement and added value, this naturally enhances its markets expansion and increase its market share by relying on services continuous improvement. The results indicated that companies management has an average interest in business practices conducive to exploring opportunities as the company accepts customer demands that exceed its existing products, through this acceptance, companies seeks to innovate new products, which enhances the companies' possession of a wide experience with the new products introduction, as well as increases the company's marketing capacity for its innovative products, so companies benefit from new opportunities in emerging markets, which requires them to find and innovate other marketing channels to market their products in these markets. Study results showed a statistically significant impact of digital marketing capabilities in its dimensions and practices on organizational ambidexterity in telecommunications companies. The results showed that the highest impact on organizational ambidexterity was for strategic approach and data content infrastructure, followed by integrating customers with employees, and finally the lowest impact was for the process of improving performance. In addition, this result indicates that digital marketing capabilities practices in telecommunications companies require workers to adapt the electronic tasks that they are accomplished in order to be ready for the new tasks they are not used to, using software of digital marketing practices system in the surveyed companies. This result agreed with Al-Sawair (2017), and the study of Shabeer (2015).

\section{Recommendations}

Based on the study findings, the researcher hopes that the decision-makers and managers have to define all tasks, roles and work procedures in companies through digital marketing systems to improve their organizational ambidexterity and enhance their performance. Conducting new studies to examine the impact of electronic human resources management (E-HRM) on organizational agility and dynamic capabilities in the researched companies. 


\section{References}

Ahmad, S., Zulkurnain, N., \&Khairushalimi, F. (2016). Assessing the Validity and Reliability of a Measurement Model in Structural Equation Modeling (SEM). British Journal of Mathematics \& Computer Science, 15(3), 1-8. https://doi.org/10.9734/BJMCS/2016/25183

Al-Hawary, S. I., \& Mohammad, A. A. (2011). The Role of the Internet in Marketing the Services of Travel and Tourism Agencies in UAE. Abhath Al-Yarmouk, 27(2B), 1339-1359.

Al-Hawary, S. I., Mohammad, A. A., \& Al-Shoura, M. (2011). The Impact of E-Marketing on Achieving Competitive Advantage by the UAEian Pharmaceutical Firms. DIRASAT, 38(1), 143-160.

Al-Hawary, S. I. S., \& Alhajri, T. M. S. (2020). Effect of Electronic Customer Relationship Management on Customers' Electronic Satisfaction of Communication Companies in Kuwait. Calitatea, 21(175), 97-102.

Al-Hawary, S. I. S., Abdul Aziz Allahow, T. J., \& Aldaihani, F. M. F. (2018). Information Technology and Administrative Innovation of the Central Agency for Information Technology in Kuwait. Global Journal of Management and Business, 18(11-A), 1-16.

Al-Hawary, S. I., \& Al-Syasneh, M. S. (2020). Impact of dynamic strategic capabilities on strategic entrepreneurship in presence of outsourcing of five stars hotels in UAE. Business: Theory and Practice, 21(2), $578-587$.

Al-Lozi, M. S., Almomani, R. Z. Q., \& Al-Hawary, S. I. S. (2018). Talent Management strategies as a critical success factor for effectiveness of Human Resources Information Systems in commercial banks working in UAE. Global Journal of Management and Business Research: A Administration and Management, 18(1), 3043.

Al-Nady, B. A., Al-Hawary, S. I., \& Alolayyan, M. (2016). The Role of Time, Communication, and Cost Management on Project Management Success: an Empirical Study on Sample of Construction Projects Customers in Makkah City, Kingdom of Saudi Arabia. International Journal of Services and Operations Management, 23(1), 76-112.

Altarifi, S., Al-Hawary, S. I. S., \& Al Sakkal, M. E. E. (2015). Determinants of E-Shopping and its Effect on Consumer Purchasing Decision in UAE. International Journal of Business and Social Science, 6(1), 81-92.

Atuahene-Gima, K. (2005). Resolving the capability - rigidity paradox in new product innovation. Journal of Marketing, 69(4), 61-83.

Birkinshaw, J., \& Gupta, K. (2013). Clarifying the distinctive contribution of ambidexterity to the field of organization studies. The Academy of Management Perspectives, 27(4), 287- 298.

Bodwell, W \& Chermack, T. (2010). Organizational ambidexterity: Integrating deliberate and emergent strategy with scenario planning. Technological Forecasting \& Social Change, 77(2), 193-202.

Canderasekaran, A. (2009). "Multiple Levels of Ambidexterity in Managing the Innovation-Improvement Dilemma: Evidence from High Technology Organizations". Dissertation, University of Minnesotaby.

de Leeuw, E., Hox, J., Silber, H., Struminskaya, B., \& Vis, C. (2019). Development of an international survey attitude scale: Measurement equivalence, reliability, and predictive validity. Measurement Instruments for the Social Sciences, 1(1), 9. https://doi.org/10.1186/s42409-019-0012-x

Emad, T. (2021) Impact of Enterprise Social Media Platforms on Integrating Inter-functional Coordination: A Moderated-Mediation effect of Optimising Staff Capabilities' Empirical Study on ICT SMEs at Gulf Cooperation Council Area' (Doctoral dissertation, University of Huddersfield).

Gartner. (2016) Digital marketing (BI) [online] C Gartner, Inc. [cit. 2018-02-07] URLhttps://www.gartner.com/itglossary/business-intel-ligence-bi/.

Gibson, B. \& Birkinshaw, J. (2014). The Antecedents, Consequences, and Mediating Role of Organizational Ambidexterity. Academy of Management Journal, 47(2), 209-226.

Hair, J. F., Babin, B. J., \&Krey, N. (2017). Covariance-Based Structural Equation Modeling in the Journal of Advertising: Review and Recommendations. Journal of Advertising, 46(1), $163-177$. https://doi.org/10.1080/00913367.2017.1281777

Hen, D., Chen, H., Lusch, R. and Li, Sh. (2011). Digital marketing architecture. IEEE Computer Society, 25(6), 13-16.

Herhausen, D., Miočević, D., Morgan, R. E., \& Kleijnen, M. H. (2020). The digital marketing capabilities gap. Industrial Marketing Management, 90, 276-290.

Hocevar, J., \& Jaklic, B. (2010). Assessing benefits of digital marketing systems - A case study, 2010. Management: Journal of Contemporary 6 Resources65 Management Issues, 15(1), 87-119.

Howard, M. C. (2018). The convergent validity and nomological net of two methods to measure retroactive influences. Psychology of Consciousness: Theory, Research, and Practice, 5(3), 324-337. https://doi.org/10.1037/cns0000149 
Isik, O., Jones, C., \& Siorova, A. (2013). Digital marketing Success: The Roles of BI Capabilities and Decision Environments. Information \& Management, 50, 13-23.

Jansen, J., Tempelaar, M. P., Van den Bosch, F. A. \& Volberda, H. W. (2009). Structural differentiation and ambidexterity: The mediating role of integration mechanisms. Organization Science, 20(4), 797-811.

Junni, P., Sarala, R. M., Taras, V. \& Tarba, S. Y. (2013). Organizational ambidexterity and performance: A metaanalysis. The Academy of Management Perspectives, 27(4), pp. 299-312.

Lubatkin, M. H., Simsek, Z., Ling, Y., \& Veiga, J. F. (2006). Ambidexterity and performance in small-to mediumsized firms: The pivotal role of top management team behavioral integration. Journal of Management, 32(5), 646-672.

Mahoney, T. (1995). The Management of Resources and the Resources of Management. Journal of Business Research, 33, 91-101.

Marchese, K., \& Dollar, B. (2015). Supply Chain Talent of the Future: findings from the third annual supply chain survey. Deloitte.

Nonaka, I., \& Takeuch, H. (1995). The Knowledge-Creating Company: How Japanese Companies Create the Dynamics of Innovation? New York: Oxford University Press.

O'Rielly, C., \& Tushman, M. L. (2013). Organizational Ambidexterity: Past, Present and Future. Academy of Management Perspectives, 27(4), 324-338.

Popovic, A., Hackney, R., Coelho, S., \& Jaklic, J. (2012) Towards Digital marketing Systems Success: Effects of Maturity and Culture on Analytical Decision Making. Decision Support Systems, 54, 729-739.

Ramakrishnan, T., Khuntia, J., Kathuria, A., \& Saldanha, T. (2016). Digital marketing Capabilities and Effectiveness: An Integrative Model. 49th Hawaii International Conference on System Sciences.

Rimkeviciene, J., Hawgood, J., O'Gorman, J., \& De Leo, D. (2017). Construct Validity of the Acquired Capability for Suicide Scale: Factor Structure, Convergent and Discriminant Validity. Journal of Psychopathology and Behavioral Assessment, 39(2), 291-302. https://doi.org/10.1007/s10862-016-9576-4

Sekaran, U., \& Bougie, R. (2016). Research methods for business: A skill-building approach (Seventh edition). Wiley.

Shi, D., Lee, T., \&Maydeu-Olivares, A. (2019). Understanding the Model Size Effect on SEM Fit Indices. Educational and Psychological Measurement, 79(2), 310-334. https://doi.org/10.1177/0013164418783530

Simsek, Z., Heavey, C., Veiga, J. F., \& Souder, D. (2009). A typology for aligning organizational ambidexterity's conceptualizations, antecedents, and outcomes. Journal of Management Studies, 46(5), 864-894.

Sung, K.-S., Yi, Y. G., \& Shin, H.-I. (2019). Reliability and validity of knee extensor strength measurements using a portable dynamometer anchoring system in a supine position. BMC Musculoskeletal Disorders, 20(1), 1-8. https://doi.org/10.1186/s12891-019-2703-0

Wang, Y. A., \& Rhemtulla, M. (2021). Power Analysis for Parameter Estimation in Structural Equation Modeling: A Discussion and Tutorial. Advances in Methods and Practices in Psychological Science, 4(1), 1-17. https://doi.org/10.1177/2515245920918253

Wasmann, M., \& Spruit, M. (2012). Performance Management within Social Network Sites: The Social Network Intelligence Process Method. International Journal of Digital marketing Research, 3(2), 49-63.

Zimmermann, A., Raisch, S. \& Birkinshaw, J. (2015). How is ambidexterity initiated? The emergent charter definition process. Organization Science, 26(4), 1119-1139.

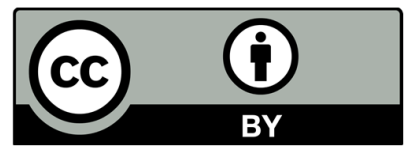

(C) 2022 by the authors; licensee Growing Science, Canada. This is an open access article distributed under the terms and conditions of the Creative Commons Attribution (CC-BY). license (http://creativecommons.org/licenses/by/4.0/). 